Como citar: Ecker, D. D. (2022). Riscos na Atenção Psicossocial: a quase inexistência do discurso 'Direitos Sociais' em saúde mental. PSI UNISC, 6(1), 82-97. doi: 10.17058/psiunisc.v6i1.16414

\title{
Riscos na Atenção Psicossocial: a quase inexistência do discurso 'Direitos Sociais' em saúde mental
}

\author{
Riesgos en la Atención Psicosocial: la casi inexistencia del discurso 'Derechos \\ Sociales' en salud mentala
}

\section{Risks in Psychosocial Care: the almost non-existence of the discourse 'Social Rights' in mental health}

\author{
Daniel Dall'Igna Ecker \\ Secretaria Municipal de Saúde de Florianopolis (SMS), Florianópolis - SC/Brasil \\ ORCID: 0000-0001-5522-2231 \\ E-mail: daniel.ecker@ hotmail.com
}

\begin{abstract}
Resumo
Este artigo tem como proposta problematizar a quase inexistência do discurso 'Direitos Sociais' no cotidiano em saúde mental da Atenção Psicossocial brasileira. Subsidiado por pesquisa de doutorado, qualitativa, de epistemologia e método inspirado no pós-estruturalismo, analisou 346 registros de experiências - 28 casos clínicos, 19 narrativas, 118 imagens, 50 documentos institucionais, 120 registros em diário de campo, 14 relatos, entre outros, sendo o presente artigo um capítulo dos resultados da tese. Através dos resultados, propõe três pontos de discussão, pensando na forma como os sujeitos produzem e conduzem a si na vida, e nos processos terapêuticos, enquanto seres subjetivos, a partir do discurso dos direitos: 1) incidência nas vidas; 2) nas terapêuticas; e, por fim, 3) através dos discursos institucionais. Por meio dos materiais infere que a nebulosidade discursiva em torno dos direitos, ao não estabelecer uma relação em língua escrita ou oral direta entre os serviços acessados, disponíveis ou não disponíveis, como contextos em que se situam o exercício dos Direitos Sociais em ato, coloca em risco a Atenção Psicossocial ao individualizar condições de vulnerabilidade social às quais muitos dos usuários e usuárias estão expostos na vida cotidiana brasileira. Com isso, propõe pensar os riscos que a inexistência do discurso dos Direitos Sociais possibilita, ao afetar no fortalecimento e preservação de um cuidado e assistência em saúde mental, baseado na perspectiva de uma saúde humana integral, biopsicossocial.
\end{abstract}

Palavras-chaves: Direitos Sociais; Atenção psicossocial; Discursos; Saúde mental.

\section{Resumen}

Este artículo tiene como objetivo problematizar la casi inexistencia del discurso 'Derechos sociales' en la salud mental cotidiana de la Atención Psicosocial Brasileña. Subsidiado por investigación de doctorado, cualitativa, de epistemología y método inspirado en el postestructuralismo, analizó 346 registros de experiencias: 28 casos clínicos, 19 narrativas, 118 imágenes, 50 documentos institucionales, 120 diarios de campo, 14 relatos, entre otros, y este artículo es un capítulo de los resultados de la tesis. A través de los resultados, propone tres puntos de discusión, pensando la forma en que los sujetos se producen y se conducen en la vida, y en los procesos terapéuticos, como seres subjetivos, desde el discurso de los derechos: 1) impacto en la vida; 2) en terapéutica; y, finalmente, 3) a través de discursos institucionales. Los materiales infieren que el enturbiamiento discursivo en torno a los derechos, al no establecer una relación directa escrita u oral entre los servicios a los que se accede, disponibles o no disponibles, como contextos en los que se sitúa el ejercicio de los Derechos Sociales, plantea que la Atención Psicosocial está en riesgo por condiciones individualizadoras. de vulnerabilidad social a la que están expuestos muchos de los usuarios en la vida cotidiana brasileña. Con ello, propone pensar sobre los riesgos que posibilita la inexistencia del discurso de los Derechos Sociales, al afectar el fortalecimiento y preservación de la atención y asistencia en salud mental, a partir de la perspectiva de una salud humana integral, biopsicosocial.

Palabras clave: Derechos Sociales; Atención psicossocial; Discursos; Salud mental.

Abstract
This article aims to problematize the almost inexistence
of the discourse 'Social Rights' in the daily mental health 
of Brazilian Psychosocial Care. Subsidized by $\mathrm{PhD}$ research, qualitative, of epistemology and method inspired by post-structuralism, analyzed 346 records of experiences - 28 clinical cases, 19 narratives, 118 images, 50 institutional documents, 120 field diary entries, 14 reports, among others, and this article is a chapter on the results of the thesis. Through the results, it proposes three points of discussion, thinking about the way subjects produce and lead themselves in life, and in the therapeutic processes, as subjective beings, from the discourse of rights: 1) impact on lives; 2) in therapeutics; and, finally, 3) through institutional speeches. The materials infer that the discursive cloudiness around rights, by not establishing a direct written or oral relationship between the services accessed, available or not available, as contexts in which the exercise of Social Rights is situated, poses Psychosocial Care is at risk by individualizing conditions of social vulnerability to which many users are exposed in Brazilian daily life. With this, it proposes to think about the risks that the inexistence of the Social Rights discourse makes possible, by affecting the strengthening and preservation of mental health care and assistance, based on the perspective of an integral, biopsychosocial human health.

Keywords: Social Rights; Psychosocial care; Discourses; Mental health.

\section{Introdução}

CAPÍTULO II

DOS DIREITOS SOCIAIS

Art. $\sigma^{\circ}$ São direitos sociais a educação, a saúde, a alimentação, o trabalho, a moradia, o transporte, o lazer, a segurança, a previdência social, a proteção à maternidade e à infância, a assistência aos desamparados.

(Constituição da República Federativa do Brasil de 1988, Art. $6^{\circ}$ ).

As políticas públicas e as políticas sociais são apresentadas como as principais vias de concretização dos Direitos Sociais [DS], através de ações, programas, políticas e serviços, que se efetivam de modos múltiplos, envolvendo acessos por contribuição e/ou nãocontributivo, focalizado e/ou universal, público e/ou privado (Viana, Fonseca \& Silva, 2017). Entretanto, principalmente no Brasil, a interrelação entre Direitos Sociais, políticas públicas, políticas sociais e intervenção do Estado, não é uma correspondência direta e consensual (Ecker, 2020). O próprio processo histórico brasileiro evidencia avanços e recuos, ao longo do tempo, alternando entre períodos de ampliação da cobertura e maior atuação do Estado na área social, com momentos de recuo parcial do Estado e adoção de políticas sociais mínimas, e/ou focalizadas nos segmentos mais pobres da população (Viana et al., 2017).

Lavinas (2016) destaca que as políticas sociais no Brasil também sofreram um processo de 'financeirização' que deterioraram as ofertas de serviços públicos, universais e gratuitos, com a priorização de produtos ofertados pelo sistema financeiro como, por exemplo, planos de saúde, financiamento estudantil, crédito direto ao consumidor, dentre outros, enfraquecendo as políticas públicas de proteção contra riscos e incertezas. No caso específico da saúde, por exemplo, o hibridismo e a financeirização das políticas públicas e sociais na América Latina evidenciam a disputa de duas principais concepções de direito à saúde: uma universalista, com base em Direitos Sociais e assegurada por um sistema único e público de saúde; outra que prioriza a cobertura e redução do risco financeiro das famílias, "com financiamento misto e fortalecimento das regras de mercado" (Viana et al., 2017, p.10).

No contexto dos diferentes níveis de complexidade do Sistema Único de Saúde (SUS), e na rede intersetorial, o hibridismo dos serviços que garantem Direitos Sociais materializa disputas também em torno dos conceitos de saúde que embasam as práticas neles executadas (Ecker \& Palombini, 2020). Termos como saúde integral, cuidado integral, integralidade, atenção integral à saúde, atenção psicossocial, dentre outros, contrapõe-se a entendimentos mais individualizados de saúde mental, que interpretam comportamentos por leituras biológicos, afetando a concepção ampliada de saúde que embasa o SUS, a saúde integral humana (Ecker \& Palombini, 2021).

Os princípios e valores da concepção de saúde biopsicossocial, que situa os agravos e doenças em diferentes determinantes em sua integralidade - biológicos, individuais, relacionais, familiares, culturais, políticos e 
sociais - estão presentes em diversas normativas e diretrizes do SUS, como na Lei $n^{\circ} 8.080$, de 19 de setembro de 1990 , e na Lei $\mathrm{n}^{\circ} 10.216$, de 6 de abril de 2001. Essas legislações afirmaram a complexidade biopsicossocial que envolve o cuidado clínico de uma saúde compreendida como integral, redirecionando o modelo de assistência às pessoas em adoecimento psíquico e remodelando a forma como a cidade organiza suas práticas de cuidado para a população (Ecker, 2020). Isso requer situar o acesso aos Direitos Sociais - saúde, educação, moradia, transporte, lazer, dentre outros -, como recursos para a produção de saúde (Ecker, 2020).

Nesse contexto, este artigo $^{1}$ tem como objetivo problematizar a quase inexistência do discurso 'Direitos Sociais' no cotidiano em saúde mental da Atenção Psicossocial brasileira. Através da análise de casos clínicos e outros materiais relacionados a saúde mental de usuários e usuárias do SUS, propõe na escrita três pontos, articulados, de discussão: 1) incidência nas vidas; 2) nas terapêuticas; e, por fim, 3 ) através dos discursos institucionais. Por meio da análise, propõe pensar os riscos que a inexistência do discurso dos Direitos Socias possibilita, ao afetar no fortalecimento e preservação de um cuidado e assistência em saúde mental, baseado na perspectiva de uma saúde humana integral, biopsicossocial.

\section{Metodologia: produção e análise dos materiais}

O presente texto deriva da pesquisa ${ }^{2}$ de doutorado que teve como objetivo analisar

\footnotetext{
${ }^{1}$ Texto derivado da tese de doutorado $O$ exercício de Direitos Sociais nos processos subjetivos e terapêuticos: políticas públicas, saúde mental e atenção psicossocial que teve como objetivo analisar o exercício dos Direitos Sociais nos processos subjetivos e terapêuticos a partir de práticas clínicas da Psicologia na atenção psicossocial. Para maiores informações, acessar: (Ecker, 2020)

${ }^{2}$ A pesquisa que subsidiou a Tese também compõe o Projeto guarda-chuva "Acompanhamento Terapêutico como Dispositivo de Análise e Cuidado em Redes de Atenção Psicossocial e Intersetorial" registrado na Plataforma Brasil e aprovado pelo Comitê de Ética em
}

como o exercício de Direitos Sociais incide nos processos subjetivos e terapêticos em curso, na clínica em Psicologia articulada às Políticas Públicas brasileiras. O estudo foi subsidiado pela coleta de 346 registros de experiências - 28 casos clínicos, 19 narrativas, 118 imagens, 50 documentos institucionais, 120 registros em diário de campo, 14 relatos, entre outros. Em razão do recorte da discussão aqui proposta, serão apresentados fragmentos desses materiais, de forma reduzida.

Fundamentado na abordagem qualitativa (Minayo, 2007), de epistemologia e método inspirado no pós-estruturalismo (Foucault, 2010; Hüning \& Scisleski, 2018), os dados da análise derivam majoritariamente de dois projetos de extensão em Psicologia de distintas universidades brasileiras. O primeiro, Programa de Acompanhamento Terapêutico na Rede Pública - ATnaRede da Universidade Federal do Rio Grande do Sul (UFRGS). O segundo projeto de extensão Acompanhamento terapêutico: clínica e criação na cidade da Universidade Federal de Santa Catarina (UFSC). Os dois projetos realizam atendimento clínico na abordagem acompanhamento terapêutico de usuários e usuárias da rede pública municipal de serviços, encaminhados(as) pelas equipes dos serviços da rede de atenção psicossocial e intersetorial para o projeto da universidade, em razão de alguma demanda de saúde mental.

A produção dos dados ocorreu por meio de dois procedimentos realizados simultaneamente. O primeiro, por registros em diário de campo (Falkembach, 1987) com

Pesquisa do Instituto de Psicologia da UFRGS, sob Número do Parecer: 3.374.882. Assim, aos usuários e usuárias do Programa foram entregues, devidamente esclarecidos e assinados, os Termos de Consentimento que seguem a Resolução 466/2012 do Ministério da Saúde e do Conselho Nacional de Saúde (Resolução n. 466, de 12 de dezembro de 2012). Projeto de Extensão "Acompanhamento Terapêutico: clínica e criação na cidade" tem aprovação pela Pró-Reitoria de Extensão da UFSC ( ${ }^{\circ}$ 201709734) e relaciona-se ao Projeto de Pesquisa guarda-chuva "Políticas do Corpo: psicanálise e arte" registrado no SIGPEX sob n²01610796. O restante dos materiais da pesquisa é de domínio público. 
relatos dos casos clínicos acompanhados em ambos os projetos de extensão da UFRGS e UFSC. Os registros ocorreram semanalmente, de agosto de 2016 a junho de 2019. Como material complementar ao diário de campo, utilizou-se materiais da pesquisa $\mathrm{GAM}^{3}$, dados do projeto ATnaRede, entre eles fichas com os dados dos acompanhados, três cadernos de atas, relatórios técnicos, cartazes, desenhos, anotações dos(as) acompanhantes e outros materiais obtidos a partir dos acompanhamentos. O segundo procedimento foi por meio do registro de experiências que remeteram à atenção psicossocial e ao contexto sócio-histórico brasileiro: imagens, documentos, relatos, entre outros, no tema da saúde mental no Brasil.

Os dados foram organizados com o objetivo de evidenciar relações possíveis entre questões subjetivas e terapêuticas de usuários(as) dos serviços de saúde mental e o exercício de Direitos Sociais, na forma como os sujeitos produzem e conduzem a si na vida, e nos processos terapêuticos, enquanto seres subjetivos. Para a apresentação de recortes dos casos clínicos, utilizou-se a formulação de narrativas escritas, as quais permitem incluir na apresentação dos dados de pesquisa a dimensão da relação na prática terapêutica entre acompanhante e acompanhado(a) (Rocha \& Palombini, 2017). Tais narrativas, mesmo quando construídas de forma dialógica, são uma produção do primeiro autor deste artigo a partir dos diários de campo, não expressando a transcrição literal de diálogos, mas a contração de seus núcleos argumentais.

Como estratégia complementar à construção das narrativas, organizou-se algumas das informações dos casos clínicos

\footnotetext{
${ }^{3}$ Materiais de pesquisa do Projeto "Implementação e descentralização da estratégia da gestão autônoma da medicação (GAM) no estado do RS: efeitos de disseminação", no qual o autor compôs como membro da equipe. A pesquisa foi um desdobramento do estudo multicêntrico, UNICAMP - UFF - UFRJ - UFRGS (2009 - 2011), que teve como objetivo construir a versão brasileira do Guia de Gestão Autônoma da Medicação (GUIA GAM-BR), traduzindo e adaptando o instrumento criado pelos serviços alternativos de saúde
}

utilizando a ferramenta do genograma e ecomapa. Esses instrumentos têm sido utilizados por profissionais de diversas áreas, incluindo a Psicologia, para compreensão dos processos estruturais, emocionais e afetivos das relações familiares, das interações entre seus membros e do contexto social mais amplo, avaliando a complexidade e dinamicidade das relações sociais (Filizola, Ribeiro \& Pavarini, 2003; Mello, Viera, Simpionato, Biasoli-Alves \& Nascimento, 2005).

A análise dos dados de inspiração pósestruturalista buscou situar o domínio da experiência terapêutica com sua sóciohistoricidade, visando a compreender como se estabelecem arranjos entre governo, verdade e sujeito (Hüning \& Guareschi, 2009) no campo da atenção psicossocial. Assim, propôs-se mapear o modo como o discurso dos Direitos Sociais - educação, saúde, alimentação, trabalho, moradia, transporte, lazer, segurança, previdência social, proteção à maternidade e à infância e assistência aos desamparados emergiu nos materiais de pesquisa e forneceu elementos para pensar como os sujeitos produzem e conduzem a si na vida, e nos processos terapêuticos, enquanto seres subjetivos. No pós-estruturalismo, a relação dos sujeitos consigo mesmos, em um momento específico (Foucault, 2010), torna-se importante à medida que evidencia verdades não como representações e essências, mas como processos: "enquanto aquilo que se faz e aquilo que se deve fazer" (Noto, 2009, p. 52) e, portanto, pode ser problematizada enquanto via "que permitiria uma infinita construção de possíveis” (Ecker, 2018, p.98).

mental no Quebec, Canadá. Direcionado às pessoas usuárias dos serviços de saúde mental, o Guia GAM possibilita criar espaços de fala sobre a experiência de uso de psicofármacos, visando compartilhar decisões a esse respeito entre profissionais dos serviços e usuários(as). $\mathrm{Na}$ pesquisa, são realizadas rodas de conversa, com a participação de pesquisadoras(es), estudantes, profissionais e usuários(as), em que se compartilha sobre as experiências da GAM nos serviços. 


\section{Resultados e discussões}

A discussão dos resultados se baseou na presença em língua escrita ou oral, ipsis litteris, do termo 'Direitos Sociais', 'Direito Social', 'direito' e 'direitos' nos materiais da pesquisa. A escolha dessa abordagem visa explicitar a presença desses termos, nos discursos cotidianos, em contextos relacionados a saúde mental.

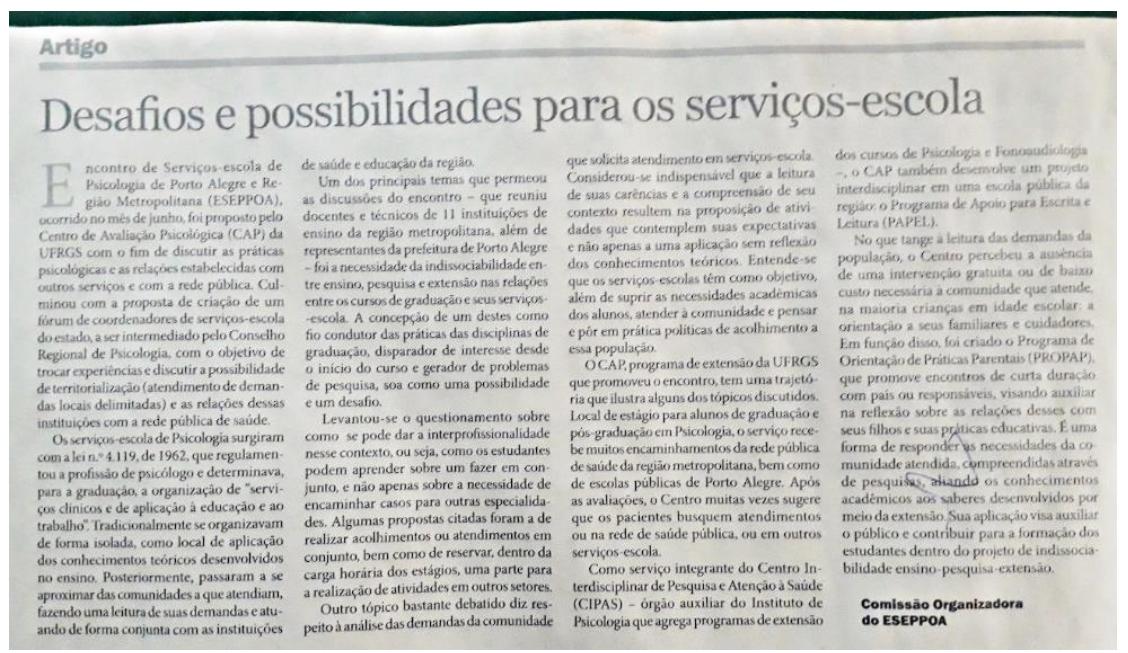

Figura 1. Reportagem publicada sobre serviços-escola de Psicologia demonstra a importância da promulgação de leis federais, que regulamentam através da oficialização de discursos na criação, ampliação, aperfeiçoamento e articulação de serviços públicos, incluindo os de exercício dos Direitos Sociais, que disponibilizam recursos e subsídios para a vida da população brasileira.

Fonte: Foto do autor. Reportagem de domínio público, disponível em mural da UFRGS.

Fragmento do texto da reportagem: Os serviços-escola de Psicologia surgiram com a lei n. ${ }^{\circ} 4.119$, de 1962, que regulamentou a profissão de psicólogo (DS ao trabalho) e determinava, para a graduação (DS à educação), a organização de "serviços clínicos e de aplicação à educação e ao trabalho" (DS à educação; DS ao trabalho) (...) Entende-se que os serviços-escolas têm como objetivo, além de suprir as necessidades acadêmicas dos alunos (DS à educação), atender à comunidade e pensar e pôr em prática políticas de acolhimento a essa população (parênteses nossos).

Historicamente, no Brasil, a inserção do termo Direitos Sociais nos discursos de representantes políticos e sua oficialização como língua escrita, em leis ou outras regulamentações nacionais, estaduais e municipais, foram imprescindíveis para o desenvolvimento do Estado nacional, possibilitando o exercício de direitos para uma parcela significativa da população (Ibanhes, 2010). A promulgação de políticas públicas e o desenvolvimento de serviços derivados desses discursos, leis e regulamentações, tornaram possível contemplar demandas da população, protegendo-a em diferentes graus e níveis de proteção social (legislação, saúde, previdência, educação, etc.) (Ibanhes, 2010), o que demanda situar a importância desses dispositivos discursivos na forma como as pessoas produzem e conduzem a si na vida, e nos processos terapêuticos, enquanto enquanto seres subjetivos e de direitos, por intermédio da linguagem jurídica.

Analisando os materiais de pesquisa, verifica-se como o discurso dos Direitos Sociais, nos mesmos termos, permanece quase inexistente, tanto na fala das(os) profissionais da rede pública intersetorial de serviços, quanto na de usuários(as) e nos documentos analisados. Do total 346 materiais coletados, conforme referido na metodologia, apenas 3 
(três) registram a presença do termo 'Direitos

Sociais ${ }^{4}$ em seu conteúdo:

Documento 1. Fragmentos de documentos exemplificam três dos contextos discursivos em que estiveram presentes o termo 'Direitos Sociais', em língua escrita, ipsis litteris, nos materiais de pesquisa.

Com o objetivo de formar multiplicadores capazes de qualificar sua atuação pela democratização do Estado e pela garantia dos direitos sociais, o Conselho Nacional de Saúde (CNS) realiza Oficinas de Formação para o Controle Social no Sistema Único de Saúde (SUS) (p.26)

Fonte: Revista Nacional de Saúde, edição 05, ano 2, set/out, 2017. Documento de domínio público.

15 de maio é o Dia do/a Assistente Social!

Uma data para destacar essa categoria profissional que trabalha cotidianamente em defesa dos direitos sociais e pela melhoria das condições de vida da população brasileira.

Fonte: Conselho Regional de Serviço Social- 9ª Região, CRESS-SP, 2019. Documento de domínio público.

\section{HOMENAGEM-MEMÓRIA DO PPGPSI À PROFESSORA TANIA MARA GALLI FONSECA}

Tania reflete sobre os desafios que se impõem à psicologia social entre eventos como a tragédia de Mariana em MG e o retrocesso agudo dos direitos sociais no país.

Fonte: Programa de Pós-graduação em Psicologia Social e Institucional, PPGPSI/UFRGS, 2019. Documento de domínio público.

Entretanto, apesar dessa quase inexistência do termo 'Direitos Sociais', é possível verificar, nos materiais de pesquisa, a presença de palavras como educação, trabalho e saúde (Figura 1; Documento 2) que, mesmo não referidas explicitamente a direitos que são sociais, remetem aos Direitos Sociais afirmados na Constituição de 1988 e se relacionam com descrições ou serviços que os materializam no cotidiano de vida:

Documento 2. Fragmento de Laudo de Perícia Médica (Psiquiátrica) para avaliação de pedido de concessão do auxílio doença, com a presença de discursos sobre trabalho, educação e saúde em documento que compõe, formula e conduz tratamento terapêutico em saúde mental.

Laudo de Perícia Médica (Psiquiátrica)

II. Identificação do examinado:

Márcia Silva ${ }^{5}$, feminina, brasileira, solteira, nunca trabalhou, sétima série ensino fundamental.

III. Síntese processual

10. Não terá mais condições de trabalho. Não poderá mais voltar às suas atividades. $\mathrm{O}$ prognóstico é ruim, pois o curso é crônico, sem recuperação. Não há possibilidades de tratamento com remissão do quadro. Esperam-se novos e intensos surtos psicóticos de apresentação imprevisível.

11. Não vemos possibilidade de atuação em qualquer atividade laboral.

\footnotetext{
${ }^{4}$ Nenhum material foi encontrado utilizando o termo

'Direito Social' no singular.

${ }^{5}$ Nome e dados pessoais fictícios.
} 
V. Diagnóstico: Transtorno afetivo bipolar - CID10 F31; Retardo Mental moderado - CID10 F71.

k) Neste transtorno mental não é um órgão que está comprometido, mas uma série de funções nobres de natureza clínica, emocional e cognitiva.

Fonte: Dados do Diário de Campo do autor no Programa de Acompanhamento Terapêutico da UFRGS/CIPAS.

No Documento 2, é importante situar a própria formulação dessa perícia como algo que só foi possível devido à existência do Direito Social à saúde, previsto em Constituição e à estrutura de uma política pública universal e gratuita, o SUS, com seus dispositivos em saúde mental, que configuraram um contexto para que a usuária fosse avaliada por esse(a) psiquiatra e obtivesse o laudo. Desse modo, o Documento 2 materializa a própria operacionalidade de um Direito Social (à saúde), incidindo nos processos subjetivos e terapêuticos para garantir um benefício (DS à assistência), por meio de algumas estratégias discursivas: afirma um diagnóstico ("transtorno"); supõe ações da usuária no futuro ("esperam-se novos e intensos surtos psicóticos de apresentação imprevisível"); e, também, interfere no posterior exercício de outros Direitos Sociais ("não terá mais condições de trabalho. Não poderá mais voltar às suas atividades").

Desse modo, os dados de pesquisa mostram que a inexistência do discurso sobre os Direitos Sociais, em língua escrita ou oral, ipsis litteris, não anula a presença de discursos sobre trabalho, educação e saúde, incidindo na vida dos(as) usuários, em seus processos subjetivos e terapêuticos. Descrevendo uma cena sobre o exercício de se alimentar, como ação que operacionaliza um Direito Social previsto em Constituição (DS à alimentação), essa incidência também está presente na Narrativa 1:

\section{Narrativa 1.}

- O que vocês acharam do último encontro?

- Interessante, acho que o grupo conseguiu se expressar.

- Parece que está se criando um clima de grupo que fez com que as pessoas participem mais e se sintam à vontade.

- É, achei bem bacana. Lembram da minha ideia sobre os desenhos? Já comecei a fazer.

- Ah, que bacana!

- Mas sabe o que eu acho? Que o problema ainda é a família, tem que trabalhar a família. A família que ignora o que a gente diz, se a gente fala alguma coisa eles dizem 'não dá bola que essa aí é doente. Louca'.

- Quem sabe tu incluis nos teus desenhos algo sobre isso?

- Pois é. E aquele ali, não fala?

- Talvez ele seja mais observador.

- Em compensação tu fala por ele né! Mas sobre o último encontro, o que vocês acharam?

- Tem gente que vem só para o lanchinho. O lanchinho é uma forma da barriga não ficar roncando enquanto a gente aprende.

Fonte: Dados do Diário de Campo do autor em participação na Pesquisa GAM.

Na Narrativa 1, a alimentação como um Direito Social, aparece no diálogo entre uma usuária do serviço de saúde mental (DS à saúde) e acadêmicos (DS à educação), em atividade na universidade em que era ofertada alimentação. Nesse diálogo, também não há 
uma identificação da alimentação como um direito ou um Direito Social, previsto em Constituição.

Assim, a Narrativa 1 e o fragmento do Documento 2 apontam elementos para uma análise que propõe pensar a inexistência da expressão Direito Social, ou apenas da noção de direito, como uma certa despolitização do discurso, sobrepondo ao exercício de Direitos Sociais fatores estritamente biológicos ${ }^{6}$ "transtorno" que, mesmo não sendo de um "órgão", comprometeria "uma série de funções nobres de natureza clínica, emocional e cognitiva" (Documento 2) - ou reduzindo-o a um interesse individual, passível de ser desqualificado em alguma instância por uma linguagem que se utiliza do diminutivo "tem gente que vem só para o lanchinho" (Narrativa 1). Os documentos de pesquisa também produzem indagações quanto aos modos de participação popular na vida pública (Ibanhes, 2010), que se produzem a partir dos discursos em que inexiste a ideia de DS em relação aos limiares de consciência das pessoas sobre o que é previsto como direito na Constituição Federal.

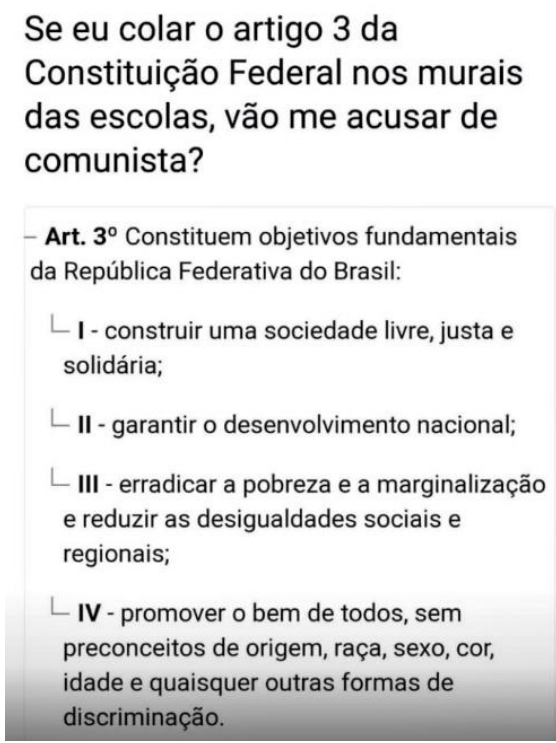

Figura 2. Publicação em rede social questiona sobre ter conhecimento da legislação brasileira e sua relação com determinados discursos da população.

Fonte: Twitter (2017). Autor desconhecido.

Se o exercício de direitos for compreendido como um exercício de cidadania, em que a amplitude de consciência da legislação incide nos moldes subjetivos com que se participa politicamente, a ideia de

\footnotetext{
${ }^{6}$ Se o tópico k) do laudo fosse realizado em outra perspectiva, priorizando a análise pelo exercício de Direitos Sociais, que são precários na vida da paciente em avaliação, poder-se-ia pensar em um discurso semelhante a este: k) Neste transtorno mental biopsicossocial, não é um Direito Social que está comprometido, mas uma série de direitos, com funções nobres para subsídio da vida humana, em que suas inexistências afetaram e afetam aspectos de natureza clínica, emocional e cognitiva (tachado nosso).

${ }^{7}$ Para Santos (1979), a proposta de cidadania regulada, ou seja, uma cidadania parcial e incompleta, é
}

cidadania regulada ${ }^{7}$, proposta por Santos (1979), também envolverá uma regulação que parte de uma estratificação identitária ou uma estratificação moral $^{8}$, estabelecida pelos discursos sociais que incidem sobre a

fundamentada pela ideia da garantia de direitos baseada "não em um código de valores políticos, mas em um sistema de estratificação ocupacional" (p.74).

${ }^{8}$ Estratificação identitária por relacionar a característica de ter conhecimento sobre a legislação brasileira como marca que comporia uma identidade, uma natureza idêntica, afinidade e semelhança com pré-determinados grupos. Estratificação moral por essa compreensão relacionar, implicitamente, os pré-determinados grupos como parâmetros para se definir o que seriam os 'bons costumes políticos', como se o não conhecer sobre política estivesse relacionado a regras de conduta 
população. Conforme mostra a Figura 2, relacionando no discurso o conhecimento da legislação como algo de uma identidade "comunista", que pode ser alvo de notificação, incriminação ou denúncia ${ }^{9}$, pode-se pensar em uma cidadania regulada pelo estabelecimento de identidades estratificadas moralmente, em uma associação com o crime ${ }^{10}$ ou demeritória, que deveria ser revelada à autoridade competente: um fato contrário à lei, à ordem pública, a algum regulamento e suscetível de punição. Destaca-se que essa produção discursiva não é algo fabricado pela existência da legislação sobre os direitos em si, mas, sim, através de como o ser humano produz afinidade com ela, nomeia identidades e as hierarquiza na relação com a linguagem jurídica.
Nesse panorama discursivo, evidenciase como a inexistência da expressão Direitos Sociais, em língua escrita ou oral, não impossibilita que outros discursos relacionados aos direitos, legislações ou linguagens jurídicas que materializam serviços de DS, incidam sobre a população e produzam efeitos nos processos de vida dos corpos que sofrem ou dos corpos que habitam a clínica em Psicologia: seja por marcas identitárias discursivamente fabricadas por uma moral hierarquizante (Figura 2), seja através de ações dos serviços pautadas pela noção de direito (Gráfico 1).

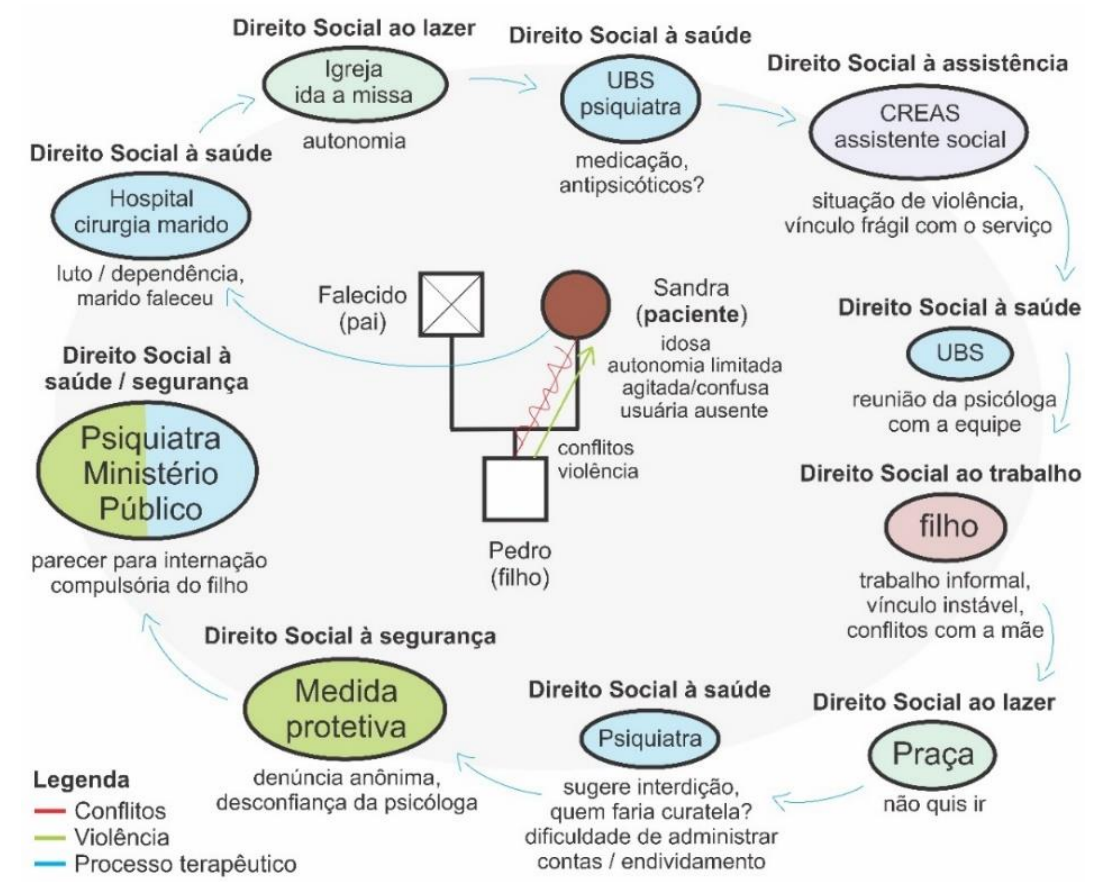

Gráfico 1. Mapeamento do percurso de usuária ${ }^{11}$ no processo de Acompanhamento Terapêutico evidencia, no período de 6 (seis) meses, alguns dos Direitos Sociais que estiveram presentes na cena clínica, produzindo efeitos através de políticas, de ações dos profissionais e de discursos sobre os direitos.

Fonte: Gráfico do autor. Dados disponíveis no caderno de registro das atas do Programa de Acompanhamento Terapêutico da UFRGS/CIPAS.

socialmente aceitas que estabelecem parâmetros do que é 'correto' ou 'ético'. Pode-se complementar aqui uma espécie de estigmatização e criminalização dos(as) defensores(as) de direitos humanos que ocorre no discurso da Figura 2.

9 Significado da palavra "acusar" presente no dicionário (Terra, 2014).

${ }^{10}$ Esse pensamento remete a discussão de Merhy (2002) quando $\mathrm{o}$ autor discute $\mathrm{o}$ projeto político-social neoliberal que, por um ideário privatizante, "opera com a noção de que qualquer forma de Direito Social conquistado é privilégio que fere as regras do mercado" (p.70).

${ }^{11}$ Para maiores informações sobre a complexidade que envolve este caso clínico, consultar: Palombini et al., 2019. 
Analisando os materiais de pesquisa, do total 346 materiais coletados, 35 (trinta e cinco) registram a presença do termo 'direito' ou "direitos" em seu conteúdo. Quando o termo 'direito' emergiu, situou-se relacionado aos Direitos Humanos (Figura 3), como algo genérico destituído de especificidade (Relato 1), relacionado ao direito à resistência (Documento 3), à informação em saúde (Relato 2) ou à saúde, entretanto, sem nomeá-lo diretamente (Figura 4). Os materiais de pesquisas que referem o DS à saúde e suas políticas relacionadas, aparecem, em especial, nos discursos daqueles(as) profissionais $\mathrm{e}$ usuários(as) vinculados(as) a movimentos sociais na área da saúde mental e em documentos de caráter institucional: conselhos profissionais (Documento 4), movimentos sociais organizados (Documento 3) e partidos políticos.

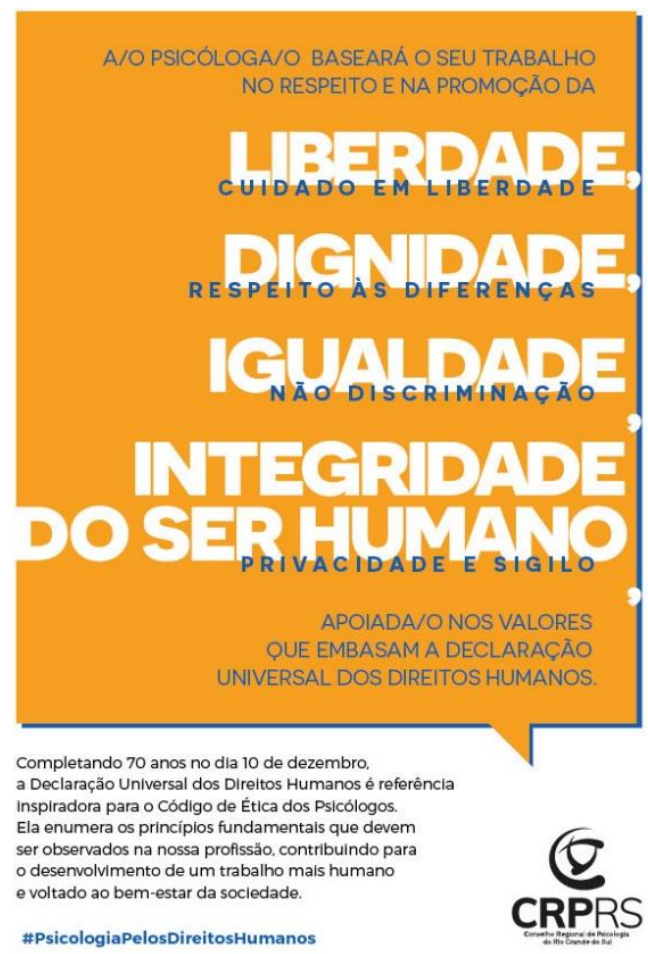

Figura 3. Contracapa da Revista EntreLinhas, publicada pelo Conselho Regional de Psicologia do Rio Grande do Sul - CRPRS, faz referência aos Direitos Humanos.

Fonte: CRPRS, 2018. Material de domínio público.

Relato 1. Discurso escrito em spray no muro do centro da cidade de Porto Alegre (RS) remete aos direitos de forma genérica, sem especificidade jurídica.

Querem tirar nossos direitos!

Fonte: Registro do autor, 2017.

Documento 3. Fragmento de texto produzido pelo Fórum Gaúcho de Saúde Mental "SOBRE LOUCURAS E FAÇANHAS: O FGSM e o 13 MENTALTCHÊ" (2018) cita o direito à resistência.

Se há façanhas que tenhamos a dar de exemplo a toda terra sabemos que elas não estão na violência de tentar apagar a história, nos autoritarismos de governos que, ao modo do Estado de exceção em que vive o Brasil, não reconheçam a legitimidade dos movimentos sociais e o direito à resistência sempre que quaisquer liberdades sejam cerceadas. Nossas verdadeiras 
façanhas estão, há mais de 30 anos, bem plantadas nesses pagos, junto àqueles que de fato aprenderam com Basaglia o quanto a liberdade é terapêutica!

Relato 2. Discurso de usuária do serviço de saúde mental, sobre tratamento em políticas do Direito Social à saúde, evidenciando dúvida sobre direito à informação em saúde.

Uma coisa que é dificultoso também é o acesso ao prontuário, né, no caso, o CID (...) Eu já tive cinco diagnósticos pelo CAPS, tem uns que nem sabem que tem direitos (...) né. Então querem saber, "ah, eu tenho direito olhar o meu prontuário", mas isso eu acho que o psiquiatra não pode fornecer, né?

Fonte: Materiais da Pesquisa GAM.

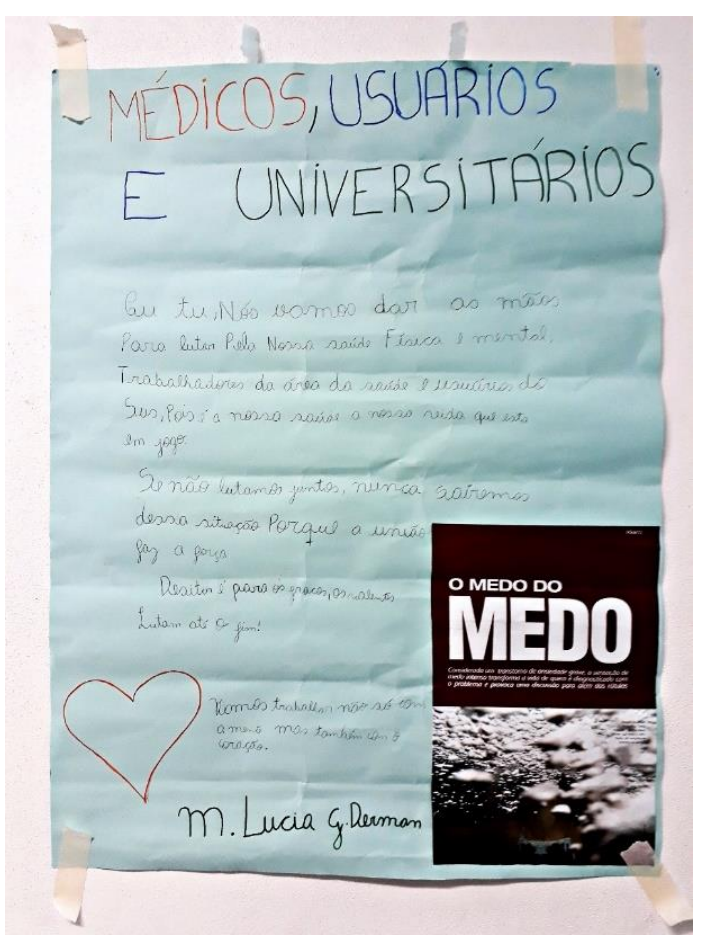

Figura 4. Cartaz formulado por usuária de serviço de saúde mental, por espontânea contribuição, é colado na parede da sala de aula do espaço universitário em que ocorreria a atividade da pesquisa sobre a Gestão Autônoma da Medicação. Nele, há menção à política do Sistema Único de Saúde sem, entretanto, nomeá-la como um direito.

Fonte: Foto do autor. Autora do material: Maria Lúcia Gonçalves Derman ${ }^{12}$.

\section{Texto do cartaz: MÉDICOS, USUÁRIOS E UNIVERSITÁRIOS}

Eu tu, Nós vamos dar as mãos Para lutar Pela Nossa saúde Física e mental. Trabalhadores da área da saúde e usuários do Sus, Pois é nossa saúde a nossa vida que esta em jogo. Se não lutamos juntos, nunca sairemos dessa situação Porque a união faz a força. Desistir é para os fracos, os valentes Lutam até o fim! Vamos trabalhar não só com a mente mas também com o coração.

\section{Reportagem colada: O MEDO DO MEDO}

Considerada um transtorno de ansiedade grave, a sensação de medo intenso transforma a vida de quem é diagnosticado com o problema e provoca uma discussão para além dos rótulos.

12 Todos os materiais em que consta identificação de autoria foi por solicitação, com autorização, das próprias autoras(es). 
Documento 4. Fragmento de notícia veiculada no site do Conselho Regional de Psicologia do Rio Grande do Sul de título: "CRPRS manifesta-se junto a outras entidades sobre a situação das emergências de Saúde Mental em Porto Alegre" (07/11/2019) cita discurso sobre direitos e suas violações.

(...) A situação torna-se mais preocupante, ainda, em relação às crianças e adolescentes atendidas nos Plantões de Emergência em Saúde Mental dos Prontos Atendimentos Cruzeiro do Sul (PESM/PACS) e IAPI (PESM/IAPI), que são destinados à população adulta. Pois fere o direito ao respeito, que consiste na inviolabilidade da integridade física, psíquica e moral da criança e do adolescente, referendado nos art. 12, 15, 17 e 18 do Estatuto da Criança e Adolescente (ECA) (...) A recente obra realizada no serviço (via ordem judicial) não é resolutiva para as violações de direitos, visto que o atendimento de crianças e adolescentes continua sendo no mesmo local que de adultos.

Fonte: CRPRS, 2019. Material de domínio público.

A inexistência da expressão 'Direitos Sociais' em dados da pesquisa, nos mesmos termos, é contrastada à presença da ideia de 'direitos', principalmente o DS à saúde, em diferentes contextos discursivos. Direta ou indiretamente, o uso da expressão 'direitos' incide na vida cotidiana, evidenciando relação com os seguintes efeitos: na interferência sobre as práticas profissionais em saúde, em como elas produzem e conduzem a si (Figura 3); na produção de denúncias, de um corpo que precisa expressar um posicionamento, por compreender que algo lhe está sendo destituído (Relato 1); no posicionamento de coletivos organizados, repreendidos em sua autonomia por órgãos de Estado, que utilizam o discurso do direito como estratégia para proteger sua integridade (Documento 3); como uma via de expressar um desconhecimento e obter maior consciência e autonomia sobre o próprio tratamento (Relato 2); como forma de expressão individual, de articulação para mobilização coletiva, solicitação de apoio e parcerias (Figura 4); no modo como as políticas públicas são operacionalizadas, violadas em suas diretrizes, demandando estratégias e tomadas de posição institucionais para proteção das regulamentações previstas em legislação brasileira (Documento 4).

Assim, os dados de pesquisa contribuem para pensar os múltiplos efeitos que se transversalizam, a partir do discurso sobre 'direitos', requerendo considerar a complexidade na análise sobre a incidência deles nos processos subjetivos e terapêuticos. Essa complexidade também envolve diferentes sujeitos sobre os quais os discursos incidem: usuárias(os) das políticas públicas, população em geral, profissionais, grupos organizados e instituições envolvidas com práticas nos serviços públicos, na saúde e em saúde mental (Figura 3; Relato 1; Documento 3; Relato 2; Figura 4; Documento 4). Conforme Ibanhes (2010), no que se refere ao Brasil, é preciso considerar que as políticas de garantia de direitos expressam contradições referentes às mazelas econômico-sociais e aos efeitos do estrangulamento político dos anos da ditadura. Destaca-se, através dos dados de pesquisa, que esses efeitos permanecem mesmo após trinta anos de término do período ditatorial (Documento 4; Figura 5). 


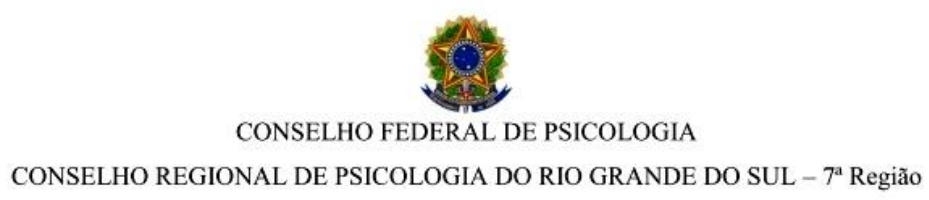

NOTA SOBRE O "PACOTE DO GOVERNO ESTADUAL"

PROTOCOLADO EM 22 DE NOVEMBRO DE 2016

O Conselho Regional de Psicologia do Rio Grande do Sul se posiciona publicamente em contrariedade às vinte $\mathrm{e}$ duas medidas protocoladas em 22 de novembro do corrente ano pelo Poder Executivo Estadual do Rio Grande do Sul junto à Assembleia Legislativa que compõem

o chamado "Pacote do Governo Estadual". As propostas - sete Propostas de Emenda à Constituição Estadual (PECs), onze Projetos de Lei (PLs) e quatro Projetos de Lei Complementar (PLCs) - estão disponíveis em publicação de 23 de novembro de 2016 do Diário Oficial da Assembleia Legislativa e em divulgação da Agência de Notícias da Assembleia Legislativa do Rio Grande do Sul, conforme consta

Figura 5. Nota do CRPRS sobre "Pacote do Governo Estadual" do Rio Grande do Sul demonstra a relação entre ações de governo e a operacionalidade das políticas de Direitos Sociais.

Fonte: Foto do autor. Conselho Regional de Psicologia do Rio Grande do Sul - CRPRS (2016).

Fragmento de texto da nota: Se houver aprovação em votação junto à Assembleia Legislativa do Rio Grande do Sul, o "Pacote do Governo Estadual" impactará a população gaúcha através do desmonte de políticas de Estado (...) O "Pacote do Governo Estadual” corrobora a imposição de um novo Estado, mais autoritário e voltado a interesses específicos com foco na lógica de mercado. Esta lógica precariza o setor público por meio do enxugamento da máquina pública e da redução de investimentos, tencionando a privatização e a terceirização como únicas alternativas possíveis. Somado a isso, potencializa a desqualificação e a criminalização dos servidores públicos.

Por meio da análise dos discursos dos 'direitos', nos materiais de pesquisa, pode-se pensar que os efeitos do estrangulamento político são verificados em situações como: ações por parte do Estado que violam direitos (Documento 3; 4); produção de políticas e intervenções inadequadas à manutenção da dignidade humana (Documento 3; Relato 1; Figura 4); desrespeito ao regime democrático (Documento 3; 4; Figura 5); e violação das legislações brasileiras, atualmente vigentes, para proteção de parcelas específicas da população (Relato 2; Documento 4; Figura 5). Esses dados podem ser relacionados ao argumento de Lo Vuolo (2016), quando este afirma que no Brasil haveria uma instabilidade econômica estrutural a refletir um sistema de proteção social incapaz de atuar como instrumento anticíclico das condições de vulnerabilidade. A lógica de intervenções neoliberais, que valorizam uma sociedade mercantil (Viana et al., 2017), e a 'financeirização' das políticas sociais, como processos que deterioram as ofertas de serviços públicos, universais e gratuitos (Lavinas, 2016), também são possíveis articular aos dados do estudo (Documento 4; Figura 5).

\section{Considerações finais}

$\mathrm{O}$ artigo teve como objetivo problematizar a quase inexistência do discurso 'Direitos Sociais' no cotidiano em saúde mental da Atenção Psicossocial brasileira. Através da análise de casos clínicos e outros materiais relacionados a saúde mental de usuários e usuárias do SUS, propôs na escrita três pontos de discussão, pensando na forma como os sujeitos produzem e conduzem a si na vida, e nos processos terapêuticos, enquanto seres subjetivos e de direitos: 1) incidência nas vidas; 2) nas terapêuticas; e, por fim, 3) através 
dos discursos institucionais. Por meio da análise dos resultados, possibilitou evidenciar a presença em língua escrita ou oral, ipsis litteris, do termo 'Direitos Sociais', 'Direito Social', 'direito' e 'direitos' nos materiais da pesquisa. A escolha dessa abordagem tornou possível explicitar a presença desses termos em contextos relacionados a saúde mental, oferecendo elementos para a Psicologia, e outras áreas de conhecimento, pensar os riscos que a inexistência desses discursos possibilita, ao afetar no fortalecimento e preservação de um cuidado e assistência em saúde mental baseado na perspectiva de uma saúde humana integral, biopsicossocial.

Infere-se, através dos materiais de pesquisa, que a nebulosidade discursiva em torno dos direitos, ao não estabelecer uma relação em língua escrita ou oral direta entre os serviços acessados, disponíveis ou não disponíveis, como contextos em que se situam o exercício dos Direitos Sociais em ato, coloca em risco a Atenção Psicossocial ao individualizar condições de vulnerabilidade social às quais muitos dos usuários e usuárias estão expostos, naturalizando a falta de acesso às políticas de garantia dos DS, que têm configurado, de maneira particular, a vida cotidiana de muitos brasileiros. Essas iniquidades tornam-se evidentes pelos paradoxos, contradições, instabilidades, incongruências, precariedades e/ou inexistências com que as políticas públicas incidem em questões subjetivas e terapêuticas. Expressando conjunturas de uma determinada época sócio-histórica, resultam, então, na fragilização de dispositivos para o cuidado em saúde mental, na perspectiva da integralidade, que contemple diferentes fatores humanos físicos, subjetivos e sociais -, nos processos diários da vida (Hullen, 2018), como juridicamente prevê os princípios do Sistema Único de Saúde do Brasil.

Verifica-se que, mesmo o sujeito sendo compreendido pelos valores e princípios do SUS como um corpo humano produzido na relação inerente entre questões biológicas, psicológicas, políticas e sociais, a expressão 'Direitos Sociais', nos mesmos termos, não foi visualizada na maioria dos materiais de pesquisa, afastando seu reconhecimento na língua oral enquanto termo envolto na produção e condução de vida das pessoas. Ao mesmo tempo, embora na conclusão seja constatado que não há referência ao termo 'Direitos Sociais', tal como ele é explicitado na Constituição, alguns materiais analisados se aproximam do termo em múltiplas roupagens e sentidos, demonstrando que o termo desliza, aparecendo para desaparecer depois, tornandose contraditório, dentre outras interpretações possíveis, lhe conferindo um caráter multifacetado.

Por fim, destaca-se sua quase inexistência nos discursos, em que a expressão 'direitos' emerge sem nomear diretamente cada Direito Social quando esse é materializado implícita ou explicitamente, tornando vago, confuso e homogêneo os discursos sobre os 'direitos'. 'Direitos Sociais', ipsis litteris, praticamente inexiste como termo nos discursos analisados referentes a processos subjetivos e terapêuticos. Essa constatação possibilita pensar que ocorre o risco de certa despolitização do discurso na Atenção Psicossocial e em algumas esferas da clínica, na compreensão sobre saúde, adoecimento e terapêuticas, sobrepondo, aos corpos, fatores biológicos, estratificações morais ou identitárias.

\section{Referências}

\section{Constituição da República Federativa do} Brasil de 1988. (1988). DF: Brasília. Recuperado de http://www.planalto.gov.br/ccivil_03/ constituicao/constituicao.htm
Ecker, D. D. (2018). Direitos Sociais e Acompanhamento Terapêutico: problematizações através de desenhos. Aurora: revista de arte, mídia e política, 11(32), 95-109. Recuperado de 
https://revistas.pucsp.br/index.php/aurora/ar ticle/view/31984

Ecker, D. D. (2020). O exercício de Direitos

Sociais nos processos subjetivos e

terapêuticos: políticas públicas, saúde

mental e atenção psicossocial (Tese de

Doutorado). Instituto de Psicologia,

Programa de Pós-Graduação em Psicologia

Social e Institucional, Universidade Federal

do Rio Grande do Sul, RS, Brasil.

Recuperado de

http://hdl.handle.net/10183/213918

Ecker, D. D., \& Palombini, A. L. (2020). A

complexidade dos direitos sociais na clínica em psicologia: Fatores materiais, singulares e multidimensionais. Pensando Psicología, 16(2), 1-28. Recuperado de https://revistas.ucc.edu.co/index.php/pe/arti cle/view/3938

Ecker, D. D., \& Palombini, A. L. (2021). Acompanhamento Terapêutico e Direitos Sociais: Territórios existenciais e sujeito biopsico-político-social. Psicologia Clínica, 33(2), 357-378. Recuperado de https://dx.doi.org/10.33208/PC19805438v0033n02A08

Falkembach, E. M. F. (1987). Diário de campo: um instrumento de reflexão. Contexto e educação, 2(7), 19-24.

Recuperdo de http://www.unirio.br/cchs/ess/Members/silv ana.marinho/disciplina-instrumentos-etecnicas-de-intervencao/unid-2instrumentos-de-conhecimentointervencao-e-registro/texto-7-falkembachelza-maria-fonseca-diario-de-campo-uminstrumento-de-reflexao-in-contexto-eeducacao-no-7-jui-inijui-1987

Filizola, C. L. A., Ribeiro, M. C., \& Pavarini S. C. I. (2003). A história da família de Rubi e seu filho Leão: trabalhando com famílias de usuários com transtorno mental grave através do modelo Calgary de avaliação e de intervenção na família. Texto e Contexto Enfermagem, 12(2), 182-190.

Recuperado de https://pesquisa.bvsalud.org/portal/resource /pt/li1-460563

Foucault, M. (2010). A hermenêutica do sujeito. São Paulo: Martins Fontes.
Hullen, A. C. N. (2018). Cidadania e direitos sociais no Brasil: um longo percurso para o acesso aos direitos fundamentais. Revista da Secretaria do Tribunal Permanente de Revisão, 6(11), 213-227. doi: 10.16890/rstpr.a6.n11.p213

Hüning, S. M., \& Guareschi, N. M. F. (2009). Efeito Foucault: desacomodar a psicologia. In N. M. F. Guareschi, \& S. Hüning (Orgs.), Michel Foucault e a Psicologia (pp. 159-182). Porto Alegre: Edipucrs.

Hüning, S. M., \& Scisleski, A. C. C. (2018). Ressonâncias de uma epistemologia foucaultiana em psicologia social. Psicologia \& Sociedade, 30, e170632. doi: 10.1590/18 07-0310/2018v30170632

Ibanhes, L. C. (2010). A constitucionalização dos direitos sociais no Brasil: difusos e coletivos ou confusos e seletivos? BIS. Boletim do Instituto de Saúde (Impresso), 12(3), 213-219. Recuperado de http://periodicos.ses.sp.bvs.br/scielo.php?sc $\underline{\text { ript}}=$ sci_arttext\&pid=S1518-181220 $10000300002 \& \operatorname{lng}=\mathrm{pt} \& \operatorname{tlng}=\mathrm{pt}$

Lavinas L. (2016). How social developmentalism reframed social policy in Brazil. Berlin: International Research Network on Interdependent Inequalities in Latin America. (Working Paper Series, 94). Lei $n^{\circ}$ 8.080, de 19 de setembro de 1990. (1990). Dispõe sobre as condições para a promoção, proteção e recuperação da saúde, a organização e o funcionamento dos serviços correspondentes e dá outras providências. Brasília: Planalto, 1962. Recuperado de http://www.planalto.gov.br/ccivil_03/leis/L 80 80.htm

Lei $n^{\circ} 10.216$, de 6 de abril de 2001. (06 de abril de 2001). Ministério da Saúde. Dispõe sobre a proteção e os direitos das pessoas portadoras de transtornos mentais e redireciona o modelo assistencial em saúde mental. Diário Oficial da União, seção 1. Brasília: DF. Recuperado de http://www.planalto.gov.br/ccivil 03/leis/le is 2001/110216.htm

Lo Vuolo RM. (2016). The limits of redistributive policies in Latin America: complementarities between economic and 
social protection systems. In B. Fritz, L. Lavinas (eds), A moment of equality for Latin America: Challenges for redistribution. New York: Routledge.

Mello, D. F., Viera, C. S., Simpionato, E., Biasoli-Alves, Z. M. M. \& Nascimento, L. C. (2005). Genograma e ecomapa: possibilidades de utilização na estratégia de saúde da família. Revista Brasileira de Crescimento e Desenvolvimento Humano, 15(1), 78-88. Recuperado de http://pepsic.bvsalud.org/ pdf/rbcdh/v15n1/09.pdf

Merhy, E. E. (2002). Saúde: a cartografia do trabalho vivo. São Paulo: Hucitec.

Minayo, M. C. S. (2007). O desafio do conhecimento. Pesquisa qualitativa em saúde (10 ${ }^{a}$ Ed.). São Paulo: HUCITEC.

Noto, C. S. (2009). A ontologia do sujeito em Michel Foucault (Dissertação de Mestrado). Departamento de Filosofia, Faculdade de Filosofia, Letras e Ciências Humanas, Universidade de São Paulo, SP, Brasil.

Palombini, A. L., Pasini, V. L., Ecker, D. D., Castro, I. D., Silveira, J. S., Schreiner, L.,
Guerra, S. Z. (2019). Acompanhamento terapêutico: uma clínica em rede. sustento da vida entre precariedades e riscos. In $\mathrm{R}$. O. Campos... [et al.]. (Org.). SaúdeLoucura 10 (pp. 1-15, v. 1, 1ªed.). São Paulo SP: Editora Hucitec.

Rocha, L. P. \& Palombini, A. L. (2017). A clínica do Acompanhamento Terapêutico como pesquisa psicanalítica: uma escrita compartilhada entre vários. Ágora: Estudos em Teoria Psicanalítica, 20(3), 732-742. doi: 10.1590/1809-44142017003012

Santos, W. G. (1979). Cidadania e justiça: a política social na ordem brasileira. Rio de Janeiro: Campus

Terra, E. (2014). Dicionário da língua portuguesa Ernani Terra (2 $2^{\text {a }}$ Ed.). São Paulo: Rideel.

Viana, A. L. d'A, Fonseca, A. M. M, \& Silva, H. P. (2017). Proteção social na América Latina e Caribe: mudanças, contradições e limites. Cadernos de Saúde Pública, 33(Suppl. 2), e00216516. doi: $\underline{10.1590 / 0102-311 \times 00216516}$

\section{Dados sobre o autor:}

- Daniel Dall'Igna Ecker: Psicólogo Clínico residente, atua atendendo em dois Centros de Saúde do município de Florianópolis, pela Secretaria Municipal de Saúde (SMS), equipe Núcleo Ampliado de Saúde da Família e Atenção Básica (NASF-AB). Doutor em Psicologia Social e Institucional pelo Programa de Pós-Graduação em Psicologia Social e Institucional (PPGPSI) da Universidade Federal do Rio Grande do Sul (UFRGS), Porto Alegre, RS, Brasil.

\section{Financiamento:}

- Pesquisa financiada com bolsa de doutorado pela Coordenação de Aperfeiçoamento de Pessoal de Nível Superior (CAPES).

\footnotetext{
Declaração de Direito Autoral

A submissão de originais para este periódico implica na transferência, pelos autores, dos direitos de publicação impressa e digital. Os direitos autorais para os artigos publicados são do autor, com direitos do periódico sobre a primeira publicação. Os autores somente poderão utilizar os mesmos resultados em outras publicações indicando claramente este periódico como o meio da publicação original. Em virtude de sermos um periódico de acesso aberto, permite-se o uso gratuito dos artigos em aplicações educacionais e científicas desde que citada a fonte conforme a licença CC-BY da Creative Commons.
} 